\title{
A critical role for neutrophil elastase in experimental bullous pemphigoid
}

\author{
Zhi Liu, ${ }^{1}$ Steven D. Shapiro, ${ }^{2,3}$ Xiaoye Zhou, ${ }^{1}$ Sally S. Twining, ${ }^{4}$ Robert M. Senior, ${ }^{2}$ \\ George J. Giudice, ${ }^{1,4}$ Janet A. Fairley, ${ }^{1,5}$ and Luis A. Diaz ${ }^{1,5}$ \\ ${ }^{1}$ Department of Dermatology, Medical College of Wisconsin, Milwaukee, Wisconsin 53226, USA \\ ${ }^{2}$ Department of Medicine, and \\ ${ }^{3}$ Departments of Pediatrics and Cell Biology, Washington University School of Medicine, St. Louis, Missouri 63110, USA \\ ${ }^{4}$ Department of Biochemistry, Medical College of Wisconsin, Milwaukee, Wisconsin 53226, USA \\ ${ }^{5}$ The Veterans Affairs Medical Center, Milwaukee, Wisconsin 53295, USA
}

Send correspondence to: Zhi Liu, Department of Dermatology, Medical College of Wisconsin, 8701 Watertown Plank Road, Milwaukee, Wisconsin 53226, USA. Phone: (414) 456-4087; Fax: (414) 456-6518; E-mail: zhiliu@mcw.edu.

Received for publication April 10, 1998, and accepted in revised form November 19, 1999.

Bullous pemphigoid (BP) is an autoimmune skin disease characterized by subepidermal blisters and autoantibodies against 2 hemidesmosome-associated proteins, BP180 and BP230. The immunopathologic features of BP can be reproduced in mice by passive transfer of anti-BP180 antibodies. Lesion formation in this animal model depends upon complement activation and neutrophil recruitment. In the present study, we investigated the role of neutrophil elastase (NE) in antibody-induced blister formation in experimental BP. Abnormally high levels of caseinolytic activity, consistent with $\mathrm{NE}$, were detected in extracts of lesional skin and blister fluid of mice injected with anti-BP180 IgG. The pathogenic anti-BP180 IgG failed to induce subepidermal blistering in NE-null ( $\left.\mathrm{NE}^{-/}\right)$mutant mice. $N E^{-/-}$mice reconstituted with neutrophils from wild-type mice became susceptible to experimental BP. Wild-type mice given NE inhibitors ( $\alpha 1$-proteinase inhibitor and Me-O-Suc-Ala-Ala-ProVal- $\mathrm{CH}_{2} \mathrm{Cl}$ ), but not mice given cathepsin $\mathrm{G} /$ chymase inhibitors ( $\alpha 1$-antichymotrypsin or Z-Gly-LeuPhe- $\mathrm{CH}_{2} \mathrm{Cl}$ ), were resistant to the pathogenic activity of anti-BP180 antibodies. Incubation of murine skin with NE induced BP-like epidermal-dermal detachment. Finally, NE cleaved BP180 in vitro and in vivo. These results implicate NE directly in the dermal-epidermal cleavage induced by anti-BP180 antibodies in the experimental BP model.

J. Clin. Invest. 105:113-123 (2000).

\section{Introduction}

Bullous pemphigoid (BP) is an autoimmune bullous dermatosis characterized by subepidermal blisters, a dermal inflammatory infiltrate, and in vivo deposition of autoantibodies and complement components along the dermal-epidermal junction (DEJ) (1). Ultrastructural studies have shown that the DEJ separation in BP lesions occurs through the lamina lucida, the electronlucent region that separates the basal cell plasma membrane from the underlying basal lamina $(2,3)$. This split is accompanied by an extensive inflammatory infiltrate and destruction of hemidesmosomal and extracellular matrix components (2-4).

One of the main antigenic targets of BP autoantibodies is a $180-\mathrm{kDa}$ transmembrane hemidesmosomeassociated glycoprotein designated BP180 (also known as BPAG2 or type XVII collagen; ref. 5-13). The extracellular domain of this protein contains a series of collagen-like triple-helical domains. Structural studies showed that the BP180 ectodomain exists in a multimeric rod-like conformation $(14,15)$. BP autoantibodies react with at least 4 distinct antigenic sites on the BP180 ectodomain, all of which are clustered within a 45-amino acid noncollagenous stretch adjacent to the membrane-spanning domain $(12,16)$.
We have described a mouse model of $\mathrm{BP}$ that involves the passive transfer of antibodies directed against mouse BP180 (17). Neonatal BALB/c mice injected with these antibodies develop a blistering skin disease that exhibits all of the key immunopathologic features of BP. Using this animal model, we have shown that the antibody-induced lesion formation is dependent on complement activation (18) and neutrophil infiltration of the upper dermis (19). In these studies neutrophils were shown to play an essential role in blister formation in experimental BP (19). Blockage of neutrophil recruitment into skin sites resulted in the neutralization of the pathogenic activity of anti-murine BP180 (antimBP180) antibodies in mice. Proteinases and reactive free radicals from infiltrating inflammatory cells, acting either alone or synergistically, have been implicated as effector molecules contributing to tissue damage in BP lesions $(20,21)$. Neutrophil granules contain a variety of proteolytic enzymes, including elastase, cathepsin G (CG), collagenase, and gelatinase B (GB), which are known to degrade specific elements of the extracellular matrix (22-24). Upon cell activation, these enzymes are secreted into the pericellular space (22). These and other proteinases, e.g., plasmin and plasminogen activators, have been detected in BP blister fluid and within lesion- 


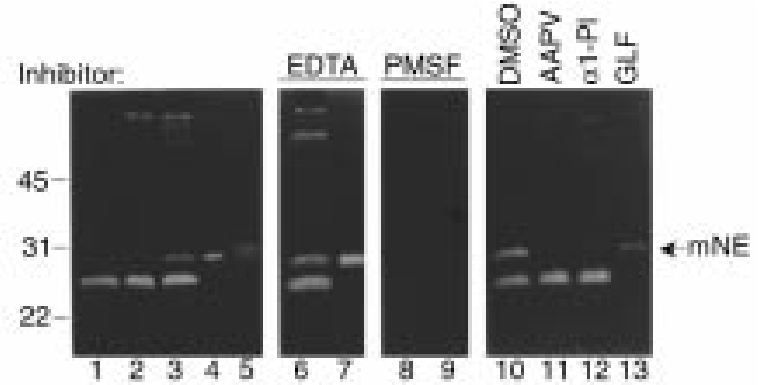

Figure 1

Casein gel zymography of experimental BP lesional skin. Skin samples $(12 \mu \mathrm{g} /$ lane) from BALB/c mice injected with PBS (lane 1), control rabbit IgG (lane 2), or pathogenic anti-mBP180 IgG (lanes 3, 6, 8, 10-13) were analyzed by casein gel zymography. Purified murine neutrophil extract ( $1 \mu \mathrm{g} /$ lane; lanes 4,7 , and 9 ) and purified human $\mathrm{NE}$ (5 ng/lane; lane 5) were used as a standard. The 29-kDa caseinolytic band comigrating with the NE standard (arrow) was completely inhibited by the serine proteinase inhibitor, PMSF (lanes 8 and 9), but not by the metalloproteinase inhibitor, EDTA (lanes 6 and 7). This activity was also blocked by neutrophil elastase inhibitor, MeoSUCAAPV-CK (AAPV, lane 11) or $\alpha 1$-PI (lane 12), but not by the CG/chymase inhibitor, GLF (lane 13) or DMSO (lane 10). mNE, murine NE.

al/perilesional skin sites on BP patients (25-31). We recently showed that GB-deficient mice are resistant to experimental BP (32); however, the relevance of other proteinases in blister formation and their cellular origin remain unresolved. In this investigation we examined the role of neutrophil elastase (NE) in blister formation in experimental $\mathrm{BP}$ using $N E^{-/-}$mutant mice.

\section{Methods}

Reagents. Human NE, CG, $\alpha 1$-proteinase inhibitor $(\alpha 1-\mathrm{PI}), \quad \alpha 1$-antichymotrypsin $\quad(\alpha 1-\mathrm{ACT}), \quad$ and myeloperoxidase (MPO) were from Athens Research and Technology, Inc. (Athens, Georgia, USA). Mouse GB was from Triple Point Biologics (Forest Grove,
Oregon, USA). PMSF, 1,10-phenanthroline, chymostatin, DMSO, casein, gelatin, and PMA were obtained from Sigma Chemical Co. (St. Louis, Missouri, USA). Methoxysuccinyl-Ala-Ala-Pro-Val-p-nitroanalide (Met-O-Suc-Ala-Ala-Pro-Val-pNA), methoxysuccinyl-Ala-Ala-Pro-Val-chloromethylketone (MeoSuc-AAPV-CK), succinyl-Ala-Ala-Pro-Phe-p-nitroanalide (Suc-Ala-Ala-Pro-Phe-pNA), and carbobenzoxy-Gly-Leu-Phe-chloromethylketone (Z-GLFCK) were from Enzyme Systems Products Inc. (Dublin, California, USA).

Laboratory animals. Breeding pairs of $\mathrm{BALB} / \mathrm{c}$ mice were purchased from The Jackson Laboratory (Bar Harbor, Maine, USA) and maintained at the Medical College of Wisconsin Animal Resource Center. NE-null mutants $\left(\mathrm{NE}^{-/-}\right)$and the matched control littermates $\left(N E^{+/+}\right)$were generated as described previously by homologous recombination in $129 \mathrm{~Sv} / \mathrm{J}$ embryonic stem (ES) cells and transmitted to germline in $129 \mathrm{~Sv} / \mathrm{J}$ $\times$ C57BL/6J background (33). Neonatal mice (24-36 hours old with body weights between 1.4 and $1.6 \mathrm{~g}$ ) were used for passive transfer experiments.

Preparation of pathogenic anti-BP180 IgG. The preparation of recombinant murine $\mathrm{BP} 180$ and the immunization of rabbits were performed as described previously (17). Briefly, a segment of the ectodomain of the murine BP180 antigen (34) was expressed as a glutathione Stransferase (GST) fusion protein using the pGEX prokaryotic expression system (Pharmacia LKB Biotech Inc., Piscataway, New Jersey, USA). The murine BP180 fusion protein, designated GST-mBP180ABC, was purified to homogeneity by affinity chromatography (35). New Zealand white rabbits were immunized with the purified $\mathrm{mBP} 180$ fusion protein, and the IgG fraction from the serum (designated R621) was purified as described previously (17). The IgG fractions were concentrated, sterilized by ultrafiltration, and the protein

Table 1

Summary: the role of neutrophil elastase in BP blister formation

\begin{tabular}{|c|c|c|c|c|}
\hline Host mice & $\operatorname{lgG}$ injected ${ }^{A}$ & Treatment & No. of mice & Disease activity ${ }^{B}$ \\
\hline & R50 & - & 18 & - \\
\hline & R621 & - & 24 & $3+$ \\
\hline & R621 & $\alpha 1-\mathrm{PI}$ & 10 & - \\
\hline \multirow[t]{3}{*}{$\mathrm{BALB} / \mathrm{c}$} & R621 & $\alpha 1-A C T$ & 10 & $3+$ \\
\hline & R621 & MeoSuc-AAPV-CK & 10 & - \\
\hline & R621 & Z-GLF-CK & 10 & $3+$ \\
\hline$N E^{+/+}$ & R621 & - & 8 & $3+$ \\
\hline$N E^{-/-}$ & R621 & - & 8 & - \\
\hline$N E^{-/-}$ & R621 & $5 \times 10^{5} \mathrm{NE}^{+/+} \mathrm{PMN}$ & 4 & $3+$ \\
\hline$N E^{-/-}$ & R621 & $5 \times 10^{5} \mathrm{NE}^{-/-} \mathrm{PMN}$ & 4 & - \\
\hline$N E^{-/-}$ & R621 & $2.5 \times 10^{6} \mathrm{NE}^{-/-} \mathrm{PMN}$ & 4 & - \\
\hline
\end{tabular}

${ }^{A}$ Neonatal BALB/c, NE-/-, and the matched control $\left(N E^{+/+}\right)$mice were injected intradermally with either nonpathogenic anti-mBP180 IgG (R50) or pathogenic antibody (R621). A NE inhibitor ( $\alpha 1-\mathrm{PI}$ or MeOSuc-AAPV-CK) or CG/chymase inhibitor ( $\alpha 1-\mathrm{ACT}$ or Z-GLF-CK) was given intradermally 90 minutes after $\operatorname{IgG}$ injection or coinjected with IgG. For neutrophil reconstitution, $N E^{-/-}$mice were given neutrophils intradermally from $N E^{+/+}$or $N E^{-/-}$mice. $\alpha 1-\mathrm{PI}, \alpha 1-\mathrm{pro}-$ teinase inhibitor; $\alpha 1$-ACT, $\alpha 1$-antichymotrypsin; MeoSuc-AAPV-CK, Met-O-Suc-Ala-Ala-Pro-Val-CH ${ }_{2} \mathrm{Cl}$; Z-GLF-CK, Z-Gly-Leu-Phe-CH${ }_{2} \mathrm{Cl}$. BInjected animals were evaluated 12 hours after IgG injection. Disease activity is scored on a scale of "-" (no detectable skin lesions) to " $3+$ " (intense erythema with frank "epidermal detachment" sign). See Methods for details. 
concentrations were determined by $\mathrm{OD}_{280 \mathrm{~nm}}(\mathrm{E}[1 \%, 1 \mathrm{~cm}]$ $=13.6)$. The titers of anti-mBP180 antibodies in both the unfractionated rabbit serum and in the purified IgG fraction were assayed by indirect immunofluorescence (IF) using mouse skin cryosections as substrate. The antibody preparations were also tested by immunoblotting against the GST-mBP180ABC fusion protein. The IF and immunoblotting techniques have been reported elsewhere (17). The pathogenicity of these IgG preparations was tested by passive transfer experiments as described below. A nonpathogenic anti-mBP180 IgG preparation (designated R50) was used as a control (19).

Induction of experimental BP and clinical evaluation of animals: Neonates were given 1 intradermal injection of a sterile solution of either control IgG or anti-BP180 IgG in PBS $(50 \mu \mathrm{L} / \mathrm{vol} ; 2.5 \mathrm{mg} \mathrm{IgG/g}$ body weight), as described elsewhere (17). The skin of neonatal mice from the test and control groups were examined 12 or 24 hours after the injection of the IgG fractions. The extent of cutaneous disease was scored as follows: (-), no detectable skin disease; $1+$, mild erythematous reaction with no evidence of the "epidermal detachment sign" (this sign was elicited by gentle friction of the mouse skin, which, when positive, produced fine, persistent wrinkling of the epidermis); $2+$, intense erythema and epidermal detachment sign involving 10-50\% of the epidermis in localized areas; and 3+, intense erythema with frank epidermal detachment sign involving more than $50 \%$ of the epidermis in the injection site.

After clinical examination, the animals were sacrificed, and skin and serum specimens were obtained. The skin samples were used for routine histological examination using light microscopy (hematoxylin and eosin [H\&E] staining) and direct IF assays to detect rabbit IgG and mouse $\mathrm{C} 3$ deposition at the basement membrane zone (BMZ). Other skin samples were used for enzymatic assays described below. The sera of injected animals were tested by indirect IF techniques to determine the titers of rabbit anti-mBP180 antibodies. Direct and indirect IF studies were performed as described previously (17) using commercially available FITC-conjugated goat anti-rabbit IgG (Kirkegaard \& Perry Laboratories Inc., Gaithersburg, Maryland, USA). Monospecific goat anti-mouse $\mathrm{C} 3$ serum was purchased from Cappel Research Products (Durham, North Carolina, USA).

Quantification of PMN accumulation at antibody injection sites. Tissue MPO activity was used as an indicator of polymorphonuclear neutrophils (PMNs) within skin samples of experimental animals, as described elsewhere (36). A standard reference curve was first established by obtaining activity levels on aliquots of known amounts of purified MPO. The mouse skin samples were extracted by homogenization in a buffer containing $0.1 \mathrm{M}$ Tris$\mathrm{Cl}, \mathrm{pH} 7.6,0.15 \mathrm{M} \mathrm{NaCl}, 0.5 \%$ hexadecyltrimethylammonium bromide. MPO activity levels in supernatant fractions were determined by the change in optical density at $460 \mathrm{~nm}$ resulting from decomposition of $\mathrm{H}_{2} \mathrm{O}_{2}$ in the presence of $o$-dianisidine. MPO content was expressed as relative MPO activity $\left(\Delta \mathrm{OD}_{460 \mathrm{~nm}} / \mathrm{mg}\right.$ pro- tein). Protein concentrations were determined by the Bio-Rad (Hercules, California, USA) dye binding assay using BSA as a standard.

Enzyme assays for $N E$ and $C G /$ chymase. NE activity in skin and neutrophil extracts of mice were measured using the NE-specific substrate Met-O-Suc-Ala-AlaPro-Val-pNA according to Nakajima et al. (37). CG/chymase activity in skin and neutrophil extracts of mice were assayed using the CG/chymase substrate Suc-AlaAla-Pro-Phe-pNA, as described by Barrett (38).

Zymographic analysis. Proteinase profiles were determined by zymography as described previously $(32,39)$. Briefly, protein extracts of neutrophils and skin samples from IgG-injected animals were subjected to SDSPAGE on casein-containing acrylamide gels (12\% acrylamide and $1 \%$ casein) or gelatin-containing acrylamide gels ( $8 \%$ acrylamide and $1 \%$ gelatin) under nonreducing conditions. After electrophoresis, gels were washed twice with $2.5 \%$ Triton X-100 for 30 minutes to remove SDS. They were then rinsed briefly with $\mathrm{H}_{2} \mathrm{O}$ and then incubated overnight at $37^{\circ} \mathrm{C}$ in reaction buffer $(50 \mathrm{mM}$ Tris, $\mathrm{pH} 7.4,150 \mathrm{mM} \mathrm{NaCl}$, and $5 \mathrm{mM} \mathrm{CaCl}_{2}$ ). The gels were stained with $0.125 \%$ Coomassie brilliant blue. Caseinolytic and gelatinolytic activity appeared as colorless zones against a blue background.

To characterize the proteinases seen on zymograms, test samples were mixed with a panel of inhibitors or negative control solvents and incubated for $15 \mathrm{~min}$ utes at room temperature before electrophoresis. The final concentrations of inhibitors were $3 \mu \mathrm{g} / \mathrm{mL} \alpha 1$ PI ( $\mathrm{H}_{2} \mathrm{O}$ as the solvent), $1 \mu \mathrm{g} / \mathrm{mL} \mathrm{MeOSuc-AAPV-CK}$ (DMSO as the solvent), $1 \mu \mathrm{g} / \mathrm{mL} \mathrm{Z}$-GLF-CK (DMSO as the solvent), $1 \mathrm{mM}$ PMSF (isopropanol as the solvent), 5 mM EDTA ( $\mathrm{H}_{2} \mathrm{O}$ as the solvent), $10 \mathrm{mM}$ 1,10phenanthroline (methanol as solvent), and $0.1 \mathrm{mM}$ chymostatin (DMSO as the solvent). After elec-

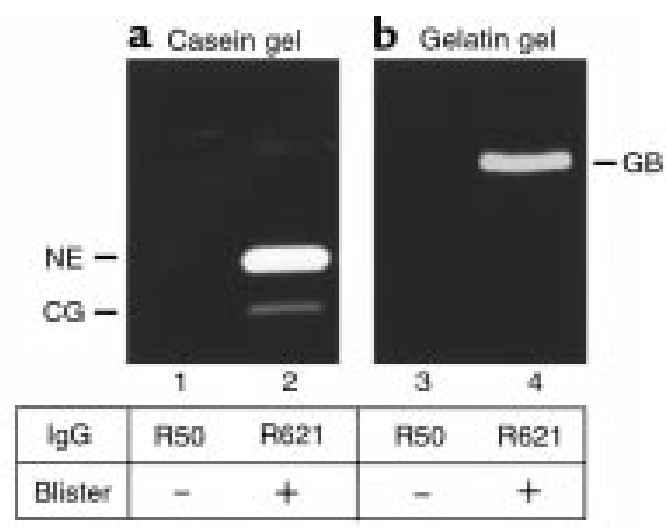

\section{Figure 2}

Identification of NE, GB, and CG in the blister fluid of experimental BP. Blister fluids ( $20 \mu \mathrm{L} /$ lane) from BALB/c mice injected with pathogenic IgG (lanes 2 and 4$)$ or PBS "washout" (20 $\mu \mathrm{L} /$ lane) from BALB/c mice injected with control IgG (lanes 1 and 3 ) were analyzed by casein (a) and gelatin (b) gel zymography. NE, (lane 2), CG (lane 2 ), and GB (lane 4) were present in the blister fluid, but not control samples (lanes 1 and 3). 


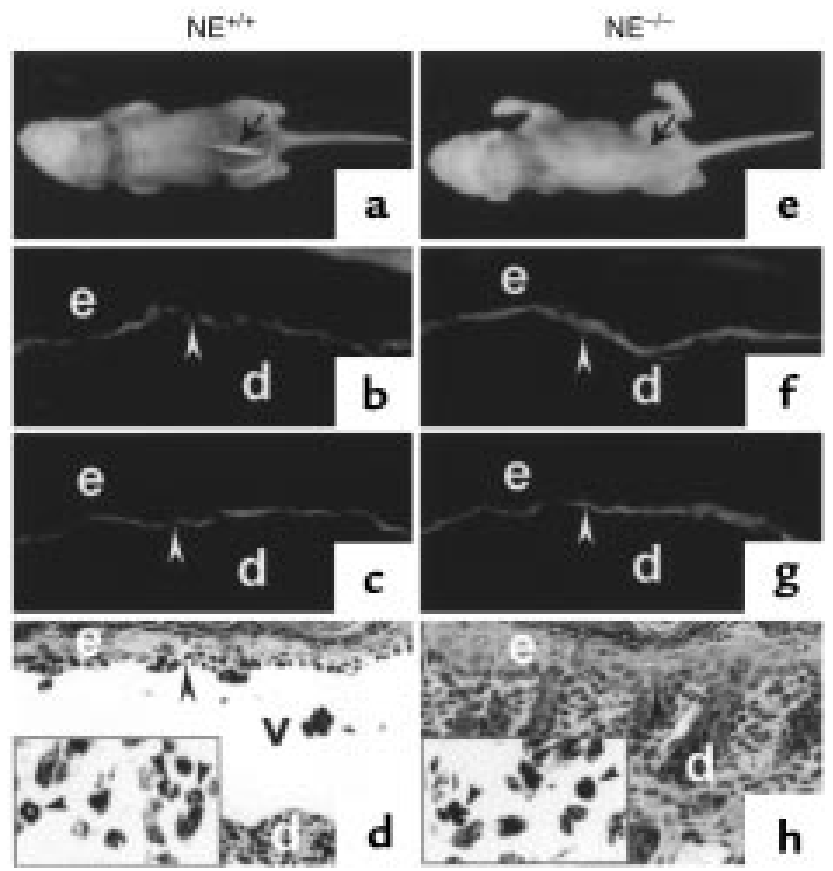

Figure 3

Clinical, IF, and histological examination of neonatal $N E^{-/-}$mice injected with rabbit anti-mBP180 IgG. Pathogenic rabbit antimBP180 IgG (intradermal injection, $2.5 \mathrm{mg} / \mathrm{g}$ body weight) produced extensive epidermal disease in neonatal $N E^{+/+}$mice. (a) The skin of these animals showed linear deposition of rabbit $\lg G(\mathbf{b})$ and mouse $\mathrm{C} 3$ (c) at the BMZ by direct IF. H\&E-stained sections from these mice showed a subepidermal vesicle with neutrophilic infiltrate (d). The inset, a higher magnification of $\mathbf{d}$, demonstrates neutrophils at the lesional site of the dermis. In contrast, neonatal $N E^{-/-}$mice injected intradermally with rabbit anti-mBP180 IgG showed no clinical evidence of skin disease (e). Direct IF studies showed rabbit IgG (f) and mouse C3 ( $\mathbf{g}$ ) deposition at the BMZ, but these animals showed no evidence of subepidermal vesiculation at the light microscopic level (h). The inset, a higher magnification of $\mathbf{h}$, exhibits neutrophils in the dermis. Site of blisters (black arrows in $\mathbf{a}$ and $\mathbf{e}$ ), site of basal keratinocytes (white arrowheads in $\mathbf{b}, \mathbf{c}, \mathbf{f}$, and $\mathbf{g}$; black arrowheads in $\mathbf{d}$ and $\mathbf{h}$ ), dermis (d), epidermis (e), vesicle (v). Original magnification, $\mathbf{b}-\mathbf{d}$ and $\mathbf{f}-\mathbf{h}: \times 100$. Inset (original magnification $\times 400$ ): neutrophils (black arrowheads).

trophoresis, the gels were washed in $2.5 \%$ Triton $\mathrm{X}$ 100 , incubated in reaction buffer, and stained with $0.125 \%$ Coomassie brilliant blue as described above. Effects of $N E$ and $C G /$ chymase inhibitors. Human $\alpha 1-\mathrm{PI}$ and $\alpha 1-\mathrm{ACT}$ were dissolved in sterile PBS. MeOSucAAPV-CK (NE inhibitor) and Z-GLF-CK (neutrophil $\mathrm{CG} /$ chymase inhibitor) were dissolved in DMSO. The doses for these inhibitors were $100 \mu \mathrm{g} / \mathrm{g}$ body weight. Each of the inhibitors (in $50 \mu \mathrm{L}$ solvent) was injected intradermally into neonatal $\mathrm{BALB} / \mathrm{c}$ mice 90 minutes after pathogenic anti-BP180 $\mathrm{IgG}$ administration $(2.5 \mathrm{mg}$ $\mathrm{IgG} / \mathrm{g}$ body weight). Alternatively, these inhibitors were coinjected intradermally with anti-BP180 IgG. Positive control mice received pathogenic anti-BP180 IgG (2.5 $\mathrm{mg} \operatorname{IgG} / \mathrm{g}$ body weight) plus $50 \mu \mathrm{L}$ solvent. Twelve hours after $\mathrm{IgG}$ injection, the injected animals were examined clinically as described above.
NE treatment of mouse skin in organ culture. Mouse skin sections were obtained from neonatal $\mathrm{BALB} / \mathrm{c}$ mice (36-48 hours old) and cut into $2 \times 2$ - $\mathrm{mm}$ strips with a razor blade. The skin strips were then incubated in MEM either with or without $100 \mu \mathrm{g} / \mathrm{mL}$ human NE at $37^{\circ} \mathrm{C}$ for various periods of time. At the end of the incubation, the skin strips were rinsed in fresh MEM, fixed in $10 \%$ formalin, and embedded in paraffin, after which sections were cut and stained with $\mathrm{H} \& \mathrm{E}$.

Neutrophil isolation and extraction. Mouse neutrophils were isolated from heparinized blood by dextran sedimentation followed by separation on a density gradient as described (40). The purified neutrophils were homogenized and extracted in the same manner as described for skin samples.

In vitro neutrophil degranulation. In vitro neutrophil degranulation assays were performed as described (41). Purified neutrophils from $N E^{+/+}$and $N E^{-/-}$mice were suspended in HBBS (GIBCO BRL, Grand Island, New York, USA) at a final concentration of $10^{7} / \mathrm{mL}$ and triggered with $50 \mathrm{ng} / \mathrm{mL}$ PMA in the absence or presence of $5 \mu \mathrm{g} / \mathrm{mL}$ MeOSuc-AAPV-CK or Z-GLF-CK for 15 minutes at $37^{\circ} \mathrm{C}$. The cells were then pelleted by centrifugation $(1,000 \mathrm{~g}, 5$ minutes), and the supernatant was analyzed by gelatin gel zymography for GB activity and enzyme assays for NE and $\mathrm{CG}$ as described above.

In vivo reconstitution of neutrophils in $\mathrm{NE}^{-/-}$mice. Neonatal $\mathrm{NE}^{-/-}$mice were injected intradermally with pathogenic anti-mBP180 IgG (2.5 mg/g body weight). Two hours later, $5 \times 10^{5}$ neutrophils from $N^{+/+}$or $5 \times 10^{5}$ or $2.5 \times 10^{6}$ neutrophils from $\mathrm{NE}^{-/-}$mice were injected into the IgG injection site. The animals were then examined 12 hours after IgG injection as described above.

Identification of $N E, G B$, and $C G$ in blister fluids. One hundred microliters of PBS was injected into the skin blisters (formed 12 hours after pathogenic IgG injection) and nonlesional sites, and withdrawn 1 minute later. The "washout" PBS was centrifuged at low speed $(1,000 \mathrm{~g})$ for 5 minutes to remove cells and then high speed $(12,000 \mathrm{~g})$ for 5 minutes to remove cell debris. The supernatant was analyzed by zymography and enzyme assays as given above.

Identification of BP180 degradation products in blisters. Protein extracts ( $55 \mu \mathrm{g} / \mathrm{lane})$ of lesional skin and nonlesional skin were resolved by 7\% SDS-PAGE gel under denaturing conditions and then immunoblotted using rabbit anti-mBP180 IgG.

In vitro degradation of recombinant murine $B P 180$ by NE. Purified GST-mBP180ABC fusion protein $(2 \mu \mathrm{g}$, as described above) was incubated with highly purified human NE $(0.125 \mu \mathrm{g})$ in the in vitro degradation buffer containing $50 \mathrm{mM}$ Tris- $\mathrm{Cl}, \mathrm{pH} 7.5$, and $1 \mathrm{mM}$ DTT. Reactions were carried out at $37^{\circ} \mathrm{C}$ for $0,0.25$, $0.5,1$, or 2 hours and terminated by adding an equal volume of SDS-PAGE sample buffer and heating at $100^{\circ} \mathrm{C}$ for 5 minutes. Reaction mixtures were then resolved by electrophoresis through $15 \%$ SDS-PAGE gels under denaturing conditions. The GST- 
$\mathrm{mBP} 180 \mathrm{ABC}$ and its degraded fragments were detected using Coomassie blue staining and immunoblotting using rabbit anti-mBP180 IgG.

Statistical analysis. The data were expressed as mean \pm SEM and were analyzed using Student's $t$ test. A $P$ value less than 0.05 was considered significant.

\section{Results}

Significantly elevated levels of $N E$ were present in experimental BP lesions and blister fluids. To identify NE, skin samples were analyzed by casein gel zymography. As shown in Figure 1, caseinolytic bands ranging from 24 to 72 $\mathrm{kDa}$ were seen in the extracts of lesional/perilesional skin of anti-BP180 IgG-injected mice (Figure 1, lane 3) in addition to the $24-\mathrm{kDa}$ band observed in extracts of control skin samples obtained from mice injected with either PBS (Figure 1, lane 1) or normal rabbit IgG (Figure 1 , lane 2 ). The caseinolytic activity associated with these bands was inhibited by PMSF (Figure 1, lane 8), a general serine proteinase inhibitor, but not by the metalloproteinase inhibitor, EDTA (Figure 1, lane 6). The 29-kDa band comigrated with murine NE (Figure 1, lanes 4 and 7). Inhibition experiments confirmed the activity as NE, because its activity could be completely blocked by the natural NE inhibitor, $\alpha 1$-PI (Figure 1, lane 11) and by the synthetic peptide NE inhibitor, MeOSuc-AAPV-CK (Figure 1, lane 12), but not by the synthetic peptide CG/chymase inhibitor, Z-GLF-CK (Figure 1, lane 13). The 24-kDa band, which was found in the skin of both anti-mBP180 IgG-injected and control mice, was identified as a CG/chymase-like proteinase, because its activity could be blocked by Z-GLFCK (Figure 1, lane 13), but not by MeOSuc-AAPV-CK (Figure 1, lane 11). These results demonstrate that elevated levels of $\mathrm{NE}$ are associated with lesional/perilesional tissue in experimental BP.

For NE to be relevant pathologically, NE would need to be released from neutrophils in the skin inflammatory site. To evaluate this, we determined the presence of NE in the skin blister fluid. Significantly high levels of NE activity were detected in the blister fluid of IgGinjected $\mathrm{NE}^{+/+}$mice (Figure 2a). Similarly, CG (Figure $2 \mathrm{a}$ ) and GB (Figure $2 \mathrm{~b}$ ) were also present in the blister fluid. These results demonstrate that NE is released from infiltrating neutrophils at lesional sites.

Elastase-deficient mice are resistant to the pathogenic effects of anti-BP180 antibodies. To determine directly whether $\mathrm{NE}$ is involved in subepidermal blister formation in experimental BP, passive transfer experiments were performed on the following 3 groups of mice: $\mathrm{NE}^{-/-}$mice, matched control littermates $\left(\mathrm{NE}^{+/+}\right)$, and positive control BALB/c mice. Mice from these 3 groups were injected intradermally with identical doses of pathogenic anti-BP180 IgG $(2.5 \mathrm{mg} / \mathrm{g}$ body weight $)$. As expected, the $\mathrm{NE}^{+/+}(n=8)$ (Figure 3a; Table 1) and $\mathrm{BALB} / \mathrm{c}(n=9)$ mice developed extensive blisters within 12 hours after injection with anti-BP180 IgG (Table 1 ). The skin of these animals was markedly erythematous and developed persistent epidermal bullous lesions. Direct IF analysis of lesional/perilesional skin of the mice showed in vivo deposition of rabbit IgG (Figure 3b) and mouse C3 (Figure 3c) at the BMZ. $\mathrm{H} \& \mathrm{E}$-stained skin sections from these mice showed DEJ separation with a neutrophil infiltration (Figure $3 \mathrm{~d}$ ). In contrast, the $\mathrm{NE}^{-1-}(n=8)$ mice (Figure 3e) exhibited no blisters 12 hours after injection with antiBP180 IgG. Indirect IF demonstrated that the titers of circulating rabbit anti-BP180 IgG in $\mathrm{NE}^{-/-}$mice were comparable to those of the control mice (average titers were greater than 1:5260 for all injected mice). Direct IF of the skin of $\mathrm{NE}^{-/-}$mice also showed deposition of rabbit IgG (Figure 3f) and mouse C3 (Figure 3g) at the $\mathrm{BMZ}$. Histologic examination of the mice skins showed no signs of dermal-epidermal detachment, but did reveal a neutrophil infiltrate in the upper dermis (Figure $3 \mathrm{~h}$ ). This inflammatory infiltrate was less prominent than the infiltrates in the skin of $\mathrm{NE}^{+/+}$mice.

Quantification of neutrophil infiltration by the MPO assay showed a significant difference between $N E^{-/-}$mice $\left(0.41 \pm 0.06 \mathrm{OD}_{460 \mathrm{~nm}} / \mathrm{mg}\right.$ protein $)$ and the control groups $\left(1.27 \pm 0.21 \mathrm{OD}_{460 \mathrm{~nm}} / \mathrm{mg}\right.$ protein for $N E^{+/+}$mice; $1.06 \pm 0.14 \mathrm{OD}_{460 \mathrm{~nm}} / \mathrm{mg}$ protein for
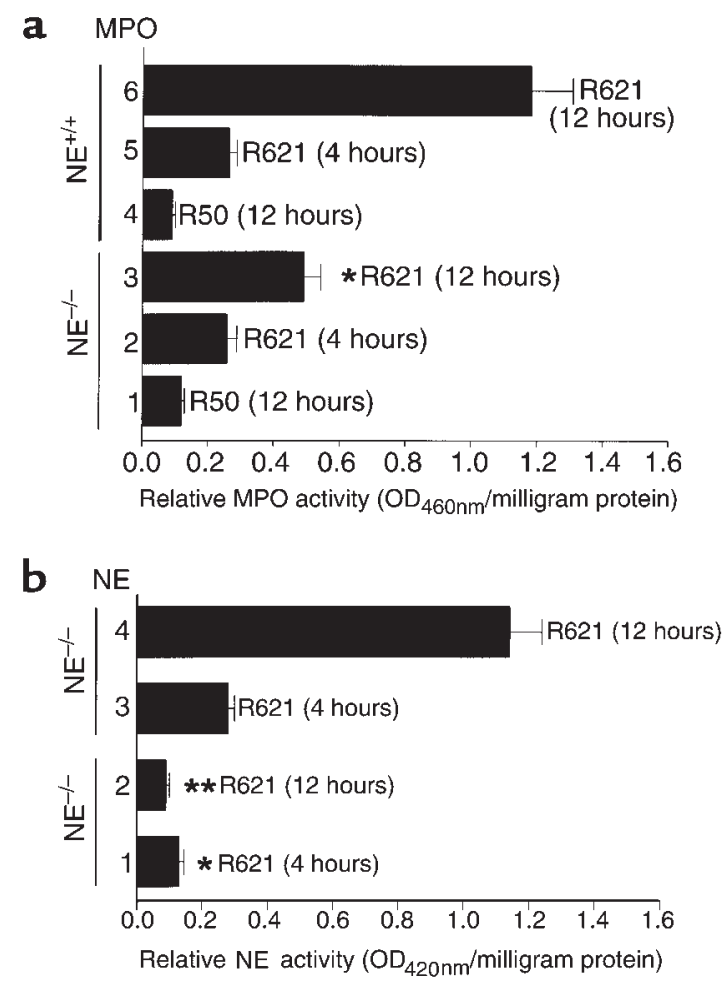

Figure 4

$\mathrm{MPO}$ and NE activities (mean $\pm \mathrm{SEM}$ ) of skin extracts from $\mathrm{NE}^{-/-}$ mice injected intradermally with pathogenic rabbit anti-mBP180 IgG. Neonatal $N E^{-/-}$(bars 1-3) and $N E^{+/+}$(bars 4-6) mice received 2.5 $\mathrm{mg} / \mathrm{g}$ body weight anti-mBP180 IgG. MPO (a) and NE (b) activities in skin at the injection sites were assayed 4 hours (bars 2 and 5 in $\mathbf{a}$; bars 1 and 3 in b) or 12 hours (bars 1, 3, 4, and 6 in a; bars 2 and 4 in b) after IgG administration. $n=8$ for $N E^{-/-}$and $N E^{+/+}$groups. ${ }^{*} P$ $<0.01 ;{ }^{*} P<0.001$. Student $t$ test for paired samples (bar 2 vs. 5 , bar 3 vs. 6 in a; bar 1 vs. 3 , bar 2 vs. 4 in b). 
a

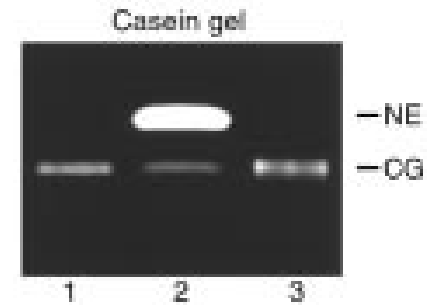

b

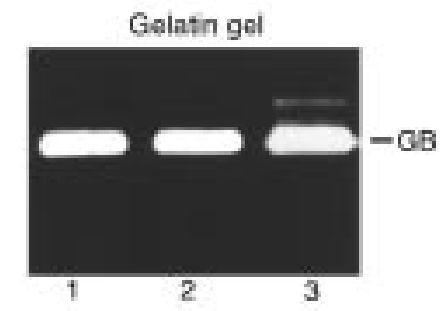

\begin{tabular}{|c|c|c|}
\hline PMN & NE $^{+}$ & \multicolumn{2}{|c|}{ NE $^{+*}$} \\
\hline AAPV & - & - \\
\hline
\end{tabular}

\section{Figure 5}

In vitro neutrophil degranulation. Neutrophils were purified from $N E^{-/-}$(lane 1) and $\mathrm{NE}^{+/+}$(lanes 2 and 3 ) mice and triggered at a final concentration of $10^{7}$ neutrophils $/ \mathrm{mL}$ with $50 \mathrm{ng} / \mathrm{mL}$ PMA in the absence (lanes 1 and 2) or presence (lane 3) of $5 \mu \mathrm{g} / \mathrm{mL} \mathrm{MeOSuc-}$ AAPV-CK (a synthetic peptide NE inhibitor) for 15 minutes at $37^{\circ} \mathrm{C}$. Cell-free releases (equivalent to $10^{5}$ neutrophils) from triggered neutrophils were analyzed by casein (a) and gelatin (b) zymography. Upon stimulation with PMA, $N E^{-/-}$(lane 1), $N E^{+/+}$(lane 2), and inhibitor-treated $\mathrm{NE}^{+/+}$(lane 3 ) neutrophils released almost the same levels of $G B$ and $C G$. $N E^{+/+}$neutrophils also secreted $N E$, whereas $N E^{-/-}$neutrophils did not. These results show that $N E^{-/-}$and inhibitor-treated $\mathrm{NE}^{+/+}$neutrophils respond normally to PMA stimulation as determined by releasing GB and CG.

$\mathrm{BALB} / \mathrm{c}$ mice; $P<0.01$ ), 12 hours after injection (Figure $4 \mathrm{a})$. In contrast, at the 4-hour time point, there were no significant differences in tissue MPO activity (Figure 4a) and CG/chymase activity (data not shown) between the $\mathrm{NE}^{-/-}$and control mice, indicating that the absence of NE activity did not interfere with the early stages of neutrophil migration from the circulation into the tissue inflammatory site.

As expected, NE activity levels (expressed as relative $\mathrm{OD}_{420 \mathrm{~nm}}$ reading/min per milligram of protein) were not above background in the antibody-treated $N E^{-/-}$ mice, but were significantly elevated in normal control mice both at 4 hours and 12 hours after injection of anti-BP180 IgG (Figure 4b). At 4 hours after IgG injection, the relative mean NE activity levels were: $0.35 \pm$ $0.03(\mathrm{BALB} / \mathrm{c}), 0.31 \pm 0.04\left(N E^{+/+}\right)$, and $0.11 \pm 0.01$ $\left(N E^{-/-} ; P<0.01\right) \mathrm{OD}_{420 \mathrm{~nm}} / \mathrm{min}$ per milligram of protein. The relative mean NE levels at the 12-hour time point were: $1.47 \pm 0.15(\mathrm{BALB} / \mathrm{c}), 1.26 \pm 0.18\left(N E^{+/+}\right)$, and 0.14 $\pm 0.02\left(\mathrm{NE}^{-/-} ; P<0.001\right) \mathrm{OD}_{420 \mathrm{~nm}} / \mathrm{min}$ per milligram of protein. These results suggest that NE plays a direct role in subepidermal blistering in experimental BP. The results of in vitro neutrophil degranulation experiments (see below) lend further support to this conclusion.
NE inhibitors block blister formation in the BP mouse model. If NE contributes directly to DEJ separation in experimental BP, then blocking NE activity should inhibit the disease phenotype. Thus, neonatal BALB/c mice were given injections of pathogenic anti-mBP180 IgG intradermally and 90 minutes later were injected at the same site with NE inhibitors ( $\alpha 1-\mathrm{PI}$ or MEOSUCAAPV-CK) or CG/chymase inhibitors ( $\alpha 1$-ACT or ZGLF-CK). Control mice (receiving R621 IgG followed by either PBS or DMSO; $n=5$ ) developed intense blisters 12 hours after antibody administration (Table 1 ). Mice coinjected with anti-mBP180 IgG and CG/chymase inhibitors $(n=5)$ also developed subepidermal blisters (Table 1). In contrast, neonatal mice that were treated with R621 IgG followed by either $\alpha 1$-PI or MeOSuc-AAPV-CK ( $n=5$ for each group) did not develop skin lesions (Table 1). The skin of these animals showed no evidence of subepidermal vesiculation, despite the presence of high levels of circulating rabbit anti-BP180 antibodies, in situ deposition of rabbit IgG and murine $\mathrm{C} 3$ at the $\mathrm{BMZ}$, and a neutrophil infiltrate in the upper dermis (data not shown). Coinjecting the $\mathrm{NE}$ inhibitor ( $\alpha 1$-PI or MeOSuc-AAPV-CK) with the pathogenic anti-BP180 IgG also yielded inhibition of subepidermal blistering (data not shown).

Neutrophil infiltration into the antibody injection sites of the animals listed above was quantified using the MPO assay. A significant difference in extractable MPO activity levels between these groups became apparent 12 hours after injection. The relative mean MPO level for mice treated with both anti-BP180 IgG and an elastase inhibitor, $\alpha 1$-PI, was $0.48 \pm 0.04$ $\mathrm{OD}_{460 \mathrm{~nm}} / \mathrm{mg}$ protein, whereas the MPO level for the control groups was $0.90 \pm 0.10 \mathrm{OD}_{460 \mathrm{~nm}} / \mathrm{mg}$ protein $(P<0.01)$. To rule out the possibility that the reduction in MPO activity in NE inhibitor-treated mice is due to the direct inhibition of neutrophil recruitment by the inhibitors, MPO activities of skin extracts in the injection sites were analyzed 4 hours after IgG injection. No change in tissue MPO activity was observed in either NE inhibitor-treated or control mice 4 hours after injection of anti-BP180 $\operatorname{IgG}(0.25 \pm 0.03$ for NE inhibitor-treated mice versus $0.29 \pm 0.03$ for control). The higher MPO values at 12 hours after mice were injected with pathogenic IgG alone are due to the development of tissue injury in the DEJ causing additional neutrophil recruitment between 4 and 12 hours after injection.

The experiments discussed above demonstrate that anti-BP180 antibodies are not capable of inducing a BP-like skin disease in $\mathrm{NE}^{-/-}$mice and in $\mathrm{BALB} / \mathrm{c}$ mice treated with NE inhibitors, suggesting that NE plays a key role in the pathogenic mechanism of experimental BP. The possibility remained, however, that the release and/or activity of other neutrophil products, e.g., GB and CG, are adversely affected in the $N E^{-/-}$and inhibitor-treated animals. To address this important issue, we performed in vitro neutrophil degranulation experiments following the protocol by 


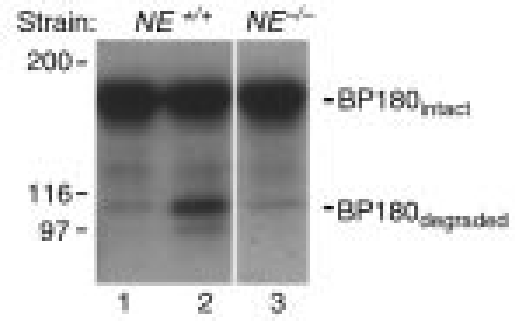

\begin{tabular}{|l|ll|l|}
\hline R50 & + & - & - \\
R621 & - & + & + \\
\hline Bistar & - & + & - \\
\hline
\end{tabular}

\section{Figure 6}

Identification of BP180 degradation products in the lesional skin of experimental BP. Neonatal $\mathrm{NE}^{+/+}$(lanes 1 and 2 ) and $\mathrm{NE}^{-/-}$(lane 3 ) mice were injected intradermally $(2.5 \mathrm{mg} / \mathrm{g}$ body weight) with control IgG R50 (lane 1) or pathogenic IgG R621 (lanes 2 and 3). Skin biopsies were obtained at 12 hours after $\lg G$ injection, and protein extracts $(45 \mu \mathrm{g} /$ lane $)$ were analyzed by immunoblotting using the anti-mBP180 IgG. Degraded BP180 band was present in the lesional skin samples of $\mathrm{NE}^{+/+}$mice injected with pathogenic IgG (lane 2), but not in the nonlesional skin samples from control IgG-injected $N E^{+/+}$(lane 1) or pathogenic IgG-injected $N E^{-/-}$mice (lane 3 ).

Desrochers et al. (41). Upon stimulation with PMA, $\mathrm{NE}^{-/-}$(Figure 5, lane 1), $\mathrm{NE}^{+/+}$(Figure 5, lane 2), and inhibitor-treated $\mathrm{NE}^{+/+}$(Figure 5, lane 3) neutrophils released similar levels of $C G$ and $\mathrm{GB}$, as determined by zymography. NE was found to be released by $N E^{+/+}$ (Figure 5a, lane 2), but not $N E^{-/-}$(Figure 5a, lane 1 ) and inhibitor-treated $\mathrm{NE}^{+/+}$(Figure 5a, lane 3) neutrophils. These results demonstrate that $\mathrm{NE}^{-/-}$and $\mathrm{NE}$ inhibitor-treated $\mathrm{NE}^{+/+}$neutrophils show the normal stimulation response.

$\mathrm{NE}$ is required for $\mathrm{BP} 180$ degradation in the lesional skin of experimental BP and produces dermal-epidermal separation in a mouse skin organ culture system. The appearance of NE in the skin correlated with subepidermal blistering in response to pathogenic IgG, thus suggesting that NE may cleave BP180 and other extracellular matrix proteinase directly. To test this hypothesis, protein extracts from lesional and nonlesional skin of IgG-injected $\mathrm{NE}^{+/+}$and $\mathrm{NE}^{-/-}$mice were analyzed by immunoblotting using rabbit antimBP180 IgG. As shown in Figure 6, both full-length $(180 \mathrm{kDa})$ and degraded $(100 \mathrm{kDa}) \mathrm{mBP} 180$ were identified in lesional skin of IgG-injected $\mathrm{NE}^{+/+}$mice (Figure 6, lane 2), whereas the nonlesional skin extracts of $\mathrm{NE}^{-/-}$mice injected with pathogenic IgG (Figure 6, lane 3 ) and $\mathrm{NE}^{+/+}$mice injected with control IgG R50 (Figure 6, lane 1) showed only intact mBP180.

Tissue damage caused by exogenous NE was also assessed using an in vitro system. Neonatal mouse skin sections $(2 \times 2 \mathrm{~mm})$ were incubated with purified human NE $(100 \mu \mathrm{g} / \mathrm{mL}$ in MEM $)$ and examined histologically at various times over a 24-hour period (Figure 7). The NE-treated skin sections showed signs of early DEJ separation at 6 hours (Figure $7 \mathrm{~b}$ ) and broad subepidermal vesiculation at 12 hours (Figure 7c). Complete detachment of the epidermis from the dermis was observed at 24 hours (Figure $7 \mathrm{~d}$ ). The control mouse skin incubated with MEM alone did not show any signs of DEJ separation at any of the time points tested (Figure 7e). The NE-induced dermal-epidermal detachment was completely blocked by the NE inhibitors MeOSuc-AAPV-CK (Figure 7f) or $\alpha 1-\mathrm{PI}$ (not shown) and by coincubation with a 5 -fold molar excess of purified GST-mBP180ABC fusion protein (Figure $7 \mathrm{~g})$. CG/chymase inhibitors (Z-GLF-CK or $\alpha 1-\mathrm{ACT}$ ) had no effect on the NE-induced tissue changes (Figure $7 \mathrm{~h}$ ). These results demonstrate that NE can produce DEJ separation of mouse skin.

$N E$ degrades the ectodomain of recombinant murine BP180 antigen in vitro. To determine whether NE is capable of directly degrading the BP180 antigen, we set up in vitro degradation assays using a $42-\mathrm{kDa}$ recombinant fusion protein, GST-mBP180ABC (Figure 8a) as a substrate for NE. As shown in Figure 8b, when recombinant GSTmBP180ABC was incubated with NE, the $42-\mathrm{kDa}$ fusion protein was degraded into 3 distinct smaller fragments, with molecular weights of 34,29 , and $26 \mathrm{kDa}$ as

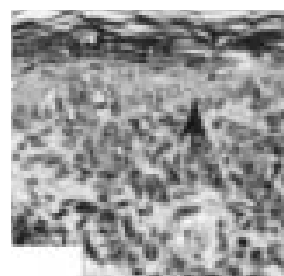

a

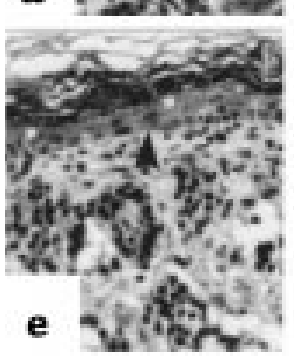

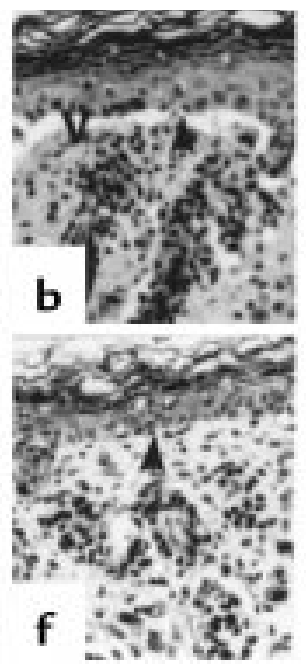

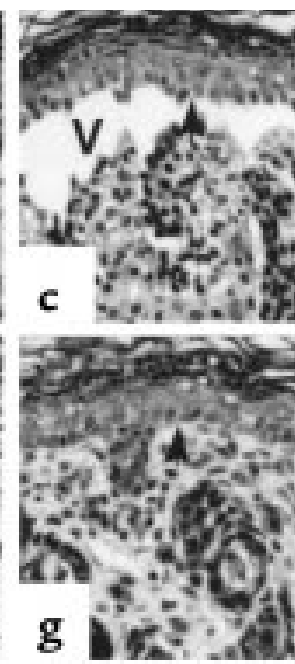

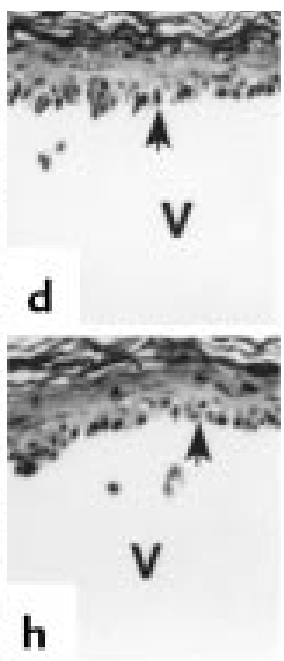

\section{Figure 7}

Generation of BP-like dermal-epidermal separation in mouse skin by NE. Neonatal mouse skin sections were incubated with $\mathrm{NE}$ at $37^{\circ} \mathrm{C}$ for 0 hours (a), 6 hours (b), 12 hours (c), or 24 hours (d-h) and were examined by H\&E staining. Dermal-epidermal separation was observed starting 6 hours after incubation. The dermal-epidermal separation was blocked by NE inhibitor MeoSUC-AAPV-CK (f) and mBP180ABC antigen (g), but not by $C G /$ chymase inhibitor Z-GLF-CK (h). Sections incubated in medium without $\mathrm{NE}$ showed no dermal-epidermal separation $(\mathbf{e})$. Site of basal keratinocytes (arrow), vesicle (v). $\times 400$. 

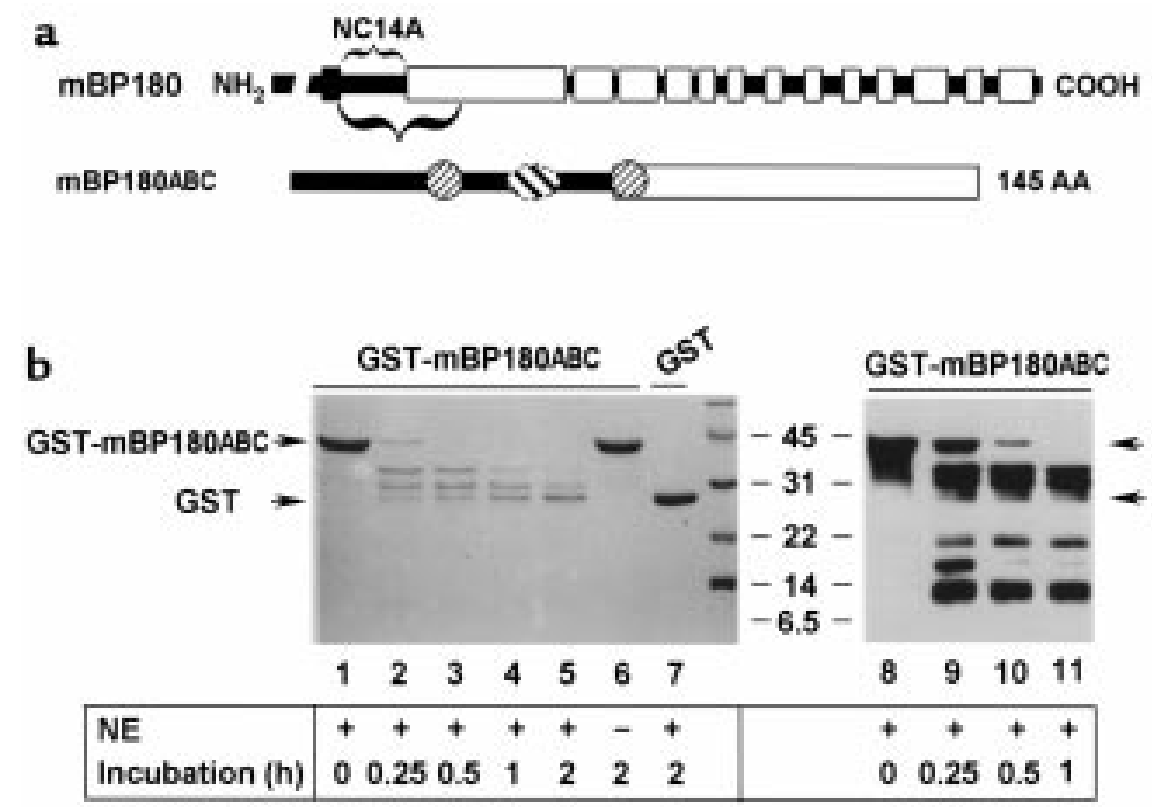

\begin{abstract}
Figure 8
In vitro degradation of $\mathrm{mBP} 180 \mathrm{ABC}$ by neutrophil elastase. (a) The schematic diagram is a structural representation of mBP180. The vertical black bar designates the transmembrane domain. The $\mathrm{COOH}$-terminal extracellular region is made up of 13 collagen triple-helical (open bar) and 14 noncollagenous (filled bar) domains. The purified recombinant GST-mBP180ABC fusion protein is $42 \mathrm{kDa}$, containing $26 \mathrm{kDa}$ GST and a 145-amino acid fragment of the mBP180 extracellular domain. The mBP180ABC is made up of an 8-kDa noncollagenous NC14A (filled bar) and an 8-kDa collagenous region (open bar). One pathogenic (oval) and 2 nonpathogenic epitopes (circles) are located within the mBP180ABC (see ref. 51). (b) The GST-mBP180ABC fusion protein (lanes 1-6, 8-11) or GST alone (lane 7) was incubated with (lanes $1-5,7-11$ ) or without (lane 6) NE at $37^{\circ} \mathrm{C}$ for 0 minutes (lanes 1 and 8 ), 0.25 hours (lanes 2 and 9 ), 0.5 hours (lanes 3 and 10 ), 1 hour (lanes 4 and 11), or 2 hours (lanes 5-7). The products were then resolved by SDS-PAGE and detected by Coomassie blue staining (lanes 1-7) or immunoblot (lanes 8-11). Fragments of $34 \mathrm{kDa}, 29 \mathrm{kDa}$, and $26 \mathrm{kDa}$ were generated from the cleavage of the fusion protein by elastase (lanes 2-5 and 9-11). No degradation products were seen after incubation without NE (lane 6). GST was not degraded by NE (lane 7). Immunoblot using anti-mBP180ABC IgG identified 3 additional fragments with molecular weights of approximately $18 \mathrm{kDa}, 15 \mathrm{kDa}$, and $9 \mathrm{kDa}$ (lanes 9-11). The immunoreactivity of these bands with anti-mBP180ABC was abolished by preadsorption of the antibody with a 5 fold molar excess of GST-mBP180ABC fusion protein, but not with GST alone (data not shown).
\end{abstract}

determined by SDS-PAGE (Figure 8b, lanes 2-5). No degradation products were seen in the reaction sample containing no NE (Figure 8b, lane 6) or containing NE at 0 time (Figure $8 b$, lane 1 ). Recombinant GST was resistant to NE digestion (Figure 8b, lane 7), indicating that the GST moiety of the GST-mBP180ABC was not a target of NE. To further characterize the NE degradation products, the digestion mixtures described above were subjected to immunoblot analysis using an anti$\mathrm{mBP} 180$ antiserum. The anti-mBP180ABC antibodies labeled the 3 bands that had been detected by Coomassie blue staining and, in addition, labeled 3 additional bands of 18,15 , and $9 \mathrm{kDa}$ (Figure $8 \mathrm{~b}$, lanes 9-11). This immunoblot staining pattern was not affected by preadsorption of the anti-BP180 serum with recombinant GST, but was completely abolished by preadsorption with GST-mBP180ABC protein (5:1 molar ratio of fusion protein/IgG; data not shown). Thus, each of these degradation products contained one or more epitopes recognized by the anti-BP180 antiserum. There appears to be at least $3 \mathrm{NE}$ cleavage sites located within the extracellular noncollagenous NC14A domain of the murine BP180 protein. These results would predict the release of $110-, 105-$, and $102-\mathrm{kDa}$ products from full-length BP180. The 102-kDa predicted fragment is similar in size to that detected in the lesional skin of experimental BP (Figure 6).

Pathogenic anti-mBP180 IgG induces subepidermal blistering in $N E^{-/-}$mice reconstituted with neutrophils from $\mathrm{NE}^{+/+}$but not $N E^{-/-}$mice. Our data show that $\mathrm{NE}$ produces DEJ separation and cleaves BP180 in vitro. However, incubation of human skin sections with human CG also produces DEJ separation (42), and GB also degrades the human recombinant BP180 ectodomain in an in vitro system (31). In addition, although in the early stage (at 4 hours after IgG injection) there is no difference in the number of infiltrating neutrophils between $\mathrm{NE}^{-/-}$and $\mathrm{NE}^{+/+}$mice, recruitment of neutrophils at the 12-hour time point is reduced in $\mathrm{NE}^{-/-}$mice (Figure 4a). Thus, resistance of $\mathrm{NE}^{-/-}$mice to experimental BP could be due to reduced levels of $\mathrm{GB}$ and/or CG. To test this possibility $N E^{-/-}$mice were injected with pathogenic IgG and reconstituted with neutrophils from either $\mathrm{NE}^{+/+}$or $\mathrm{NE}^{-/-}$mice. Twelve hours after IgG injection, the $N E^{-/-}$mice $(n=4)$ reconstituted with $5 \times 10^{5} \mathrm{NE}^{+/+}$neutrophils developed subepidermal blisters (Figure 9a, panels A and B) and cleaved BP180 antigen was detected in the lesional skin 
extracts (Figure $9 \mathrm{~b}$, lane 2 ). In contrast, $N E^{-/-}$mice $(n=$ 4) reconstituted with either $5 \times 10^{5}$ or $2.5 \times 10^{6} \mathrm{NE}^{-/-}$ neutrophils showed no sign of blistering (Figure 9a, panels $\mathrm{C}$ and D) and only intact BP180 antigen was seen in the skin extracts (Figure 9b, lanes 1 and 3). These results clearly demonstrate that NE plays a major role and GB and CG play a minimal role in the direct damage of $\mathrm{BMZ}$ in experimental $\mathrm{BP}$.

\section{Discussion}

NE has been implicated in numerous inflammatory diseases (22, 43-47). Using NE-null mutant mice, we now provide evidence that NE plays a destructive role in experimental BP, an inflammatory skin blistering disease. Our data show (a) abnormally high levels of NE in the lesional/perilesional skin and blister fluid of experimental BP mice; (b) $\mathrm{NE}^{-/-}$mice are resistant to experimental BP; (c) $\mathrm{NE}^{-/-}$mice reconstituted with $N E^{+/+}$neutrophils become susceptible to experimental BP; (d) NE inhibitors ( $\alpha 1$-PI and AAPV) block subepidermal blistering in experimental BP; (e) NE degrades BP180 and extracellular matrix components of the BMZ, causing DEJ separation in the skin culture system; and (f) NE cleaves the recombinant mBP180. These results suggest that NE is directly involved in disruption of the DEJ leading to subepidermal vesiculation in experimental BP.

We also rule out the possibility that the protective effects observed in $N E^{-/-}$mice are only transient in nature because the protection continues to be observed up to 48 hours after IgG injection (data not shown).

The BP180 ectodomain exists in an extended trimeric conformation consisting of a series of articulated collagen-like rigid rods $(14,15)$ spanning the lamina luci$\mathrm{da}$ and inserting into the lamina densa of the basement membrane $(13,48)$. It has been hypothesized that the BP180 ectodomain interacts with one or more components of the extracellular matrix, thereby stabilizing anchorage of the basal keratinocyte. Consistent with this hypothesis are the recent findings that mutations within the BP180 gene lead to the inherited blistering disease, generalized atrophic benign epidermolysis bullosa (49). NE degrades collagens (50-53), fibronectin (54), and proteoglycans $(55,56)$. The results of our in vitro enzyme digestion experiments demonstrate that NE also cleaves the extracellular domain of the BP180 protein. Thus, it is reasonable to hypothesize that degradation of cell-matrix adhesion molecules, including BP180, by NE and/or other proteolytic enzymes is an important step leading to the detachment of the basal keratinocytes from the basement membrane.

In previous studies we have shown that neutrophil migration to sites of infection was not impaired in $N E^{-/-}$mice (33). The present results further demonstrate that NE deficiency does not impair transvascular migration of neutrophils into the skin triggered by pathogenic anti-mBP180 antibodies. There was no difference in neutrophil infiltration between $\mathrm{NE}^{-/-}$mice and wild-type control mice 4 hours after the injection a
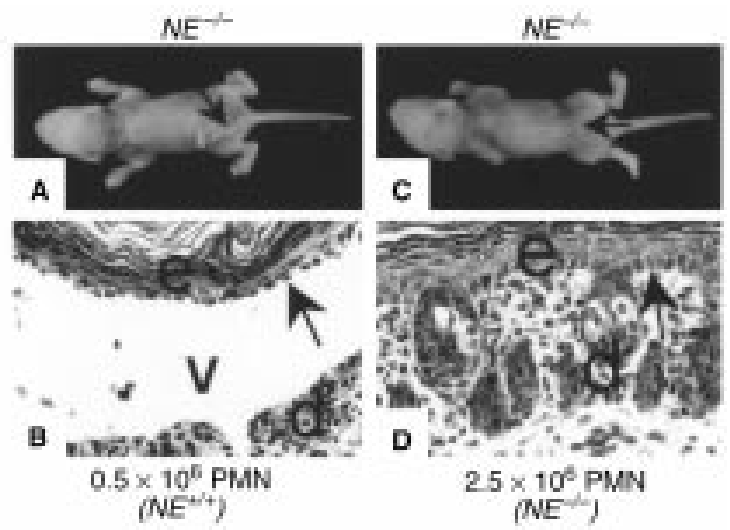

b

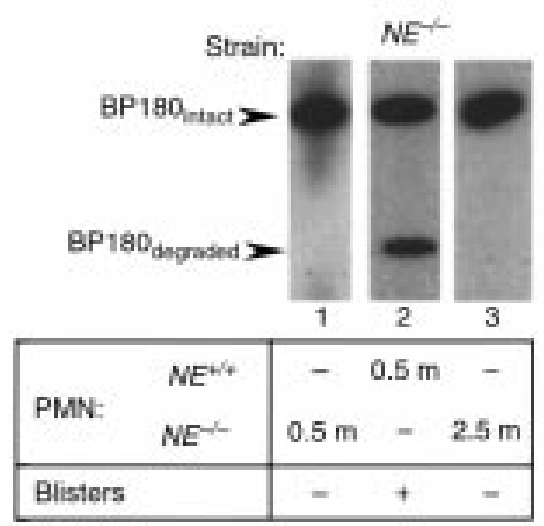

\section{Figure 9}

In vivo neutrophil reconstitution in $N E^{-/-}$mice. Neonatal $N E^{-/-}$mice were injected intradermally with pathogenic anti-mBP180 IgG $(2.5$ $\mathrm{mg} / \mathrm{g}$ body weight). Two hours later, these mice were given neutrophils from $\mathrm{NE}^{+/+}$or $\mathrm{NE}^{-/-}$mice intradermally and examined 12 hours after IgG injection. (a) Clinical and histological examination showed $N E^{-/-}$mice reconstituted with $0.5 \times 10^{6} \mathrm{NE}^{+/+}$neutrophils (panels A and B), but not with $2.5 \times 10^{6} \mathrm{NE}^{-/-}$neutrophils (panels $\mathrm{C}$ and D). (b) Immunoblotting using rabbit anti-mBP180 antibodies revealed cleaved $\mathrm{BP} 180$ antigen in $N E^{-/-}$mice reconstituted with 0.5 $\times 10^{6} \mathrm{NE}^{+/+}$neutrophils (lane 2 ), but not $0.5 \times 10^{6}$ (lane 1$)$ and 2.5 $\times 10^{6} \mathrm{NE}^{-/-}$(lane 3$)$ neutrophils.

of pathogenic IgG, when subepidermal blistering has already begun in control mice. We hypothesize that NE-mediated degradation product(s) are chemotactic for neutrophils, which would account for the higher levels of neutrophil accumulation in the later stages of the disease process in control mice compared with NEdeficient mice. This is similar to findings in macrophage elastase-deficient mice $\left(\mathrm{MME}^{-/-}\right)$that fail to accumulate macrophages in response to cigarette smoke (57). In this condition there is evidence that MME cleavage of elastin is responsible for monocyte chemotaxis (S.D. Shapiro, unpublished data).

We recently found that GB-deficient mice are also resistant to the pathogenic activity of anti-mBP180 IgG (32). GB is present in BP lesional skin and blister fluid (31). GB cleaves a number of extracellular matrix proteins (58-62), $\alpha 1$-PI (58), and recombinant BP180 (31). GB could contribute to subepidermal blistering in BP directly by cleaving structural proteins in the 
DEJ or indirectly by inactivating $\alpha 1-\mathrm{PI}$, the principal $\mathrm{NE}$ inhibitor. CG also produces DEJ separation when incubated with skin sections (42). Therefore, the DEJ separation triggered by pathogenic anti-BP180 IgG could be due to the proteolytic activity of $\mathrm{NE}$ alone or in concert with GB, CG, and/or other proteolytic enzymes. In fact, we found that neutrophil extracts from $N E^{-/-}$mice incubated with mouse skin sections produce DEJ separation and cleave the recombinant mouse BP180 ectodomain. These data indicate that other proteinases may participate in these events, at least in vitro (data not shown). The exact relationship between NE, GB, CG, and other proteinases in experimental BP is under investigation.

Despite the striking similarities in the immunopathological features of the experimental model of $\mathrm{BP}$ and the human disease, there is one conspicuous difference. The human disease is characterized by an inflammatory infiltrate predominated by eosinophils (4), whereas in the mouse model, the neutrophil is the major inflammatory cell type at the lesional site (17). This discrepancy might signify a key difference in the pathogenic mechanisms operating in humans and mice. Whereas it is clear that the eosinophil plays only a secondary role, if any, in subepidermal blistering in the mouse model, it might be the eosinophil, rather than the neutrophil, that plays an essential role in the initiation and/or progression of human BP. However, a causal link between the presence of eosinophils and subepidermal blistering in humans with BP has not been established. On the contrary, several observations implicate neutrophils in human BP. First, neutrophil-predominant forms of BP have been described in which eosinophils are absent in the inflammatory cell infiltrate, suggesting that eosinophils are not essential for blister formation (63). Second, neutrophils were an essential component in achieving dermal-epidermal detachment in an in vitro model of BP described by Gammon et al. (64). In this model system, after incubation of cultured human skin with a BP serum, complement, and peripheral blood leukocytes, neutrophils lined up along the BMZ and breakdown of dermal-epidermal cohesion occurred. Further studies of inflammatory cells in human BP are necessary to assess the fidelity with which the BP mouse model mimics the human disease.

In summary, NE activity is essential for the generation of subepidermal blisters in experimental BP (see Table 1). It is presumed that this enzyme, acting alone or with other effector molecules, carries out this pathogenic role in $\mathrm{BP}$ by degrading components of the BMZ that function in maintaining dermal-epidermal cohesion. Degradation of one such adhesion-related molecule, BP180, appears to be a key in the pathogenic cascade leading to blister formation; i.e., the extracellular domain of this transmembrane protein is the primary antigenic target of pathogenic antibodies and is a substrate for NE. These findings are important in terms of the molecular pathogenesis of $\mathrm{BP}$ and point to new directions for the development of therapies for BP.

\section{Acknowledgments}

This work was supported in part by U.S. Public Health Service grants R29 AI-40768 (Z. Liu), R01 EY-12731 (S.S. Twining), R01 AR-40410 (G.J. Giudice), HL-54853 and HL-56414 (S.D. Shapiro), HL-47328 (R.M. Senior), and R01 AR-32599 and R37-AR32081 (L.A. Diaz) from the National Institutes of Health, by a VA Merit Review Grant (L.A. Diaz), and by the Alan A. and Edith L. Wolff Charitable Trust (R.M. Senior).

1.Jordon, R.E., et al. 1967. Basement zone antibodies in bullous pemphigoid. JAMA. 200:751-756.

2. Schaumburg-Lever, G., Orfanos, C.E., and Lever, C.E. 1971. Electron microscopic study of bullous pemphigoid. Arch. Dermatol. 106:662-667.

3. Dvorak, A.M., et al. 1982. Bullous pemphigoid, an ultrastructural study of the inflammatory response: eosinophil, basophil and mast cell granule changes in multiple biopsies of one patient. J. Invest. Dermatol. 78:91-101.

4. Anhalt, G.F., and Morrison, L. 1993. Pemphigoid: bullous, gestational and cicatricial. In Bullous diseases. T.T. Provost and W.L. Weston, editors. Mosby Year Book. St. Louis, MO. 63-114.

5. Labib, R.S., Anhalt, G.J., Patel, H.P., Mutasim, D.F., and Diaz, L.A. 1986. Molecular heterogeneity of bullous pemphigoid antigens as detected by immunoblotting. J. Immunol. 136:1231-1235.

6. Mutasim, D.F., et al. 1985. A pool of bullous pemphigoid antigen(s) is intracellular and associated with the basal cell cytoskeleton-hemidesmosome complex. J. Invest. Dermatol. 84:47-53.

7. Diaz, L.A., et al. 1990. Isolation of a human epidermal cDNA corresponding to the $180-\mathrm{kD}$ autoantigen recognized by bullous pemphigoid and herpes gestationis sera. Immunolocalization of this protein to the hemidesmosome. J. Clin. Invest. 86:1088-1094.

8. Giudice, G.J., Squiquera, H.L., Elias, P.M., and Diaz, L.A. 1991. Identification of two collagen domains within the bullous pemphigoid autoantigen, BP180. J. Clin. Invest. 87:734-738.

9. Giudice, G.J, Emery, D.J., and Diaz, L.A. 1992. Cloning and primary structural analysis of the bullous pemphigoid autoantigen, BP-180. J. Invest. Dermatol. 99:243-250.

10. Hopkinson, S.B., Riddelle, K.S., and Jones, J.C.R. 1992. Cytoplasmic domain of the $180-\mathrm{kD}$ bullous pemphigoid antigen, a hemidesmosomal component: molecular and cell biologic characterization. J. Invest. Der matol. 99:264-270.

11. Nishikawa, Y., Uematsu, J., and Owaribe, K. 1993. HD4, a 180 kDa bullous pemphigoid antigen, is a major transmembrane glycoprotein of the hemidesmosome. J. Biochem. 113:493-501.

12. Giudice, G.J., et al. 1993. Bullous pemphigoid and herpes gestationis autoantibodies recognize a common non-collagenous site on the BP180 ectodomain. J. Immunol. 151:5742-5750.

13. Bedane, C., et al. 1997. Bullous pemphigoid and cicatricial pemphigoid autoantibodies react with ultrastructurally separable epitopes on the BP180 ectodomain: evidence that BP180 spans the lamina lucida. $J$. Invest. Dermatol. 108:901-907.

14. Hirako, Y., Usukura, J., Nishizawa, Y., and Owaribe, K. 1996. Demonstration of the molecular shape of BP180, a $180-\mathrm{kDa}$ bullous pemphigoid antigen and its potential for trimer formation. J. Biol. Chem. 271:13739-13745.

15. Balding, S.D., Diaz, L.A., and Giudice, G.J. 1997. A recombinant form of the human BP180 ectodomain forms a collagen-like homotrimeric complex. Biochemistry. 36:8821-8830.

16. Zillikens, D., et al. 1997. Tight clustering of extracellular BP180 epitopes recognized by bullous pemphigoid autoantibodies. J. Invest. Dermatol. 109:573-579.

17. Liu, Z., et al. 1993. A passive transfer model of the organ-specific autoimmune disease, bullous pemphigoid, using antibodies generated against the hemidesmosomal antigen, BP180. J. Clin. Invest. 92:2480-2488.

18. Liu, Z., et al. 1995. The role of complement in experimental bullous pemphigoid. J. Clin. Invest. 95:1539-1544.

19. Liu, Z., et al. 1997. A major role of neutrophils in experimental bullous pemphigoid. J. Clin. Invest. 100:1256-1263.

20. Jordon, R.E., Kawana, S., and Fritz, K.A. 1985. Immunopathologic mechanisms in pemphigus and bullous pemphigoid. J. Invest. Dermatol. 85(Suppl.):72s-78s.

21. Gammon, W.R. 1989. Immune complex and complement-mediated leukocyte recruitment in bullous pemphigoid. Immunol. Ser. 46:509-525.

22. Weiss, S.J. 1989. Tissue destruction by neutrophils. N. Engl. J. Med. 320:365-376

23. Senior, R.M., and Campbell, E.J. 1983. Neutral proteinases from human inflammatory cells. A critical review of their role in extracellular matrix degradation. Clin. Lab. Med. 3:645-666. 
24. Janoff, A. 1985. Elastase in tissue injury. Annu. Rev. Med. 36:207-216. 25. Oikarinen, A.I., Zone, J.J., Ahmed, A.R., Kiistala, U., and Uitto, J. 1983. Demonstration of collagenase and elastase activities in blister fluids from bullous skin diseases. Comparison between dermatitis herpetiformis and bullous pemphigoid. J. Invest. Dermatol. 81:261-266.

26. Welgus, H.G., Bauer, E.A., and Stricklin, G.P. 1986. Elevated levels of human collagenase inhibitor in blister fluids of diverse etiology. J. Invest. Dermatol. 87:592-596.

27. Grando, S.A., Glukhenky, B.T., Drannik, G.N., Kostromin, A.P., and Chernyavsky, A.I. 1989. Cytotoxic proteinases in blister fluid of pemphigus and pemphigoid patients. Int. J. Tissue React. 11:195-201.

28. Grando, S.A., et al. 1989. Mediators of inflammation in blister fluids from patients with pemphigus vulgaris and bullous pemphigoid. Arch. Dermatol. 125:925-930.

29. Gissler, H.M., Simon, M.M., and Kramer, M.D. 1992. Enhanced association of plasminogen/plasmin with lesional epidermis of bullous pemphigoid. Br. J. Dermatol. 127:272-277.

30. Kramer, M.D., and Reinartz, J. 1993. The autoimmune blistering skin disease bullous pemphigoid. The presence of plasmin/ $\alpha 2$-antiplasmin complexes in skin blister fluid indicates plasmin generation in lesional skin. J. Clin. Invest. 92:978-983.

31. Ståhle-Bäckdahl, M., Inoue, M., Giudice, G.J., and Parks, W.C. 1994. 92-kD gelatinase is produced by eosinophils at the site of blister formation in bullous pemphigoid and cleaves the extracellular domain of recombinant 180-kD bullous pemphigoid autoantigen. J. Clin. Invest. 93:2022-2030.

32. Liu, Z., et al. 1998. Gelatinase B-deficient mice are resistant to experimental bullous pemphigoid. J. Exp. Med. 188:475-482.

33. Belaaouaj, A., et al. 1998. Mice lacking neutrophil elastase reveal impaired host defense against gram negative bacterial sepsis. Nat. Med. 4:615-618

34. Li, K., Tamai, K., Tan, E.M.L., and Uitto, J. 1993. Cloning of type XVII collagen. Complementary and genomic DNA sequences of mouse 180 kilodalton bullous pemphigoid antigen (BPAG2) predict an interrupted collagenous domain, a transmembrane segment, and unusual features in the $5^{\prime}$-end of the gene and the $3^{\prime}$-untranslated region of the mRNA. J. Biol. Chem. 268:8825-8834.

35. Liu, Z., Diaz, L.A., Haas, A.L., and Giudice, G.J. 1992. cDNA cloning of a novel human ubiquitin carrier protein. An antigenic domain specifically recognized by endemic pemphigus foliaceus autoantibodies is encoded in a secondary reading frame of this human epidermal transcript. $J$. Biol. Chem. 267:15829-15835.

36. Bradley, P.P., Priebat, D.A., Christensen, R.D., and Rothstein, G. 1982 Measurement of cutaneous inflammation: estimation of neutrophil content with an enzyme marker. J. Invest. Dermatol. 78:206-209.

37. Nakajima, K., Powers, J.C., Ashe, B.M., and Zimmerman, M. 1979. Mapping the extended substrate binding site of cathepsin $G$ and human leukocyte elastase. Studies with peptide substrates related to the $\alpha 1$-proteinase inhibitor reactive site. J. Biol. Chem. 254:4027-4032.

38. Barrett, A.J. 1981. Cathepsin G. Methods Enzymol. 80:561-566.

39. Twining, S.S., et al. 1996. Effect of vitamin A deficiency on the early response to experimental Pseudomonas keratitis. Invest. Ophthalmol. Vis. Sci. 37:511-522.

40. Metcalf, J.A., Gallin, J.I., Nauseef, W.M., and Root, R.K. 1985. Laboratory manual of neutrophil function. Raven Press. New York, NY. 2-10.

41. Desrochers, P.E., Mookhtiar, K., Van Wart, H.E., Hasty, K.A., and Weiss, S.J. 1992. Proteolytic inactivation of $\alpha 1$-proteinase inhibitor and $\alpha 1$ antichymotrypsin by oxidatively activated human neutrophil metalloproteinases. J. Biol. Chem. 267:5005-5012.

42. Briggaman, R.A., Schechter, N.M., Fraki, J., and Lazarus, G.S. 1984 Degradation of the epidermal-dermal junction by proteolytic enzymes from human skin and human polymorphonuclear leukocytes. J. Exp. Med. 160:1027-1042.

43. Gossage, J.R., Kuratomi, Y., Davidson, J.M., Lefferts, P.L., and Snapper, J.R. 1993. Neutrophil elastase inhibitors, SC-37698 and SC-39026, reduce endotoxin-induced lung dysfunction in awake sheep. Am. Rev. Respir. Dis. 147:1371-1379.
44. Rudolphus, A., Stolk, J., Dijkman, J.H., and Kramps, J.A. 1993. Inhibition of lipopolysaccharide-induced pulmonary emphysema by intratracheally instilled recombinant secretory leukocyte proteinase inhibitor. Am. Rev. Resp. Dis. 147:442-447.

45. Gossage, J.R., et al. 1995. Secretory leukoprotease inhibitor attenuates lung injury induced by continuous air embolization into sheep. J. Appl. Physiol. 79:1163-1172.

46. Yoshimura, K., Nakagawa, S., Koyama, S., Kobayashi, T., and Homma, T. 1994. Roles of neutrophil elastase and superoxide anion in leukotriene B4-induced lung injury in rabbit. J. Appl. Physiol. 76:91-96.

47. Vogelmeier, C., Gillissen, A., and Buhl, R. 1996. Use of secretory leukoprotease inhibitor to augment lung antineutrophil elastase activity. Chest. 110(Suppl.):261S-266S.

48. Masunaga, T., et al. 1997. The extracellular domain of BPAG2 localizes to anchoring filaments and its carboxyl terminus extends to the lamina densa of normal human epidermal basement membrane. J. Invest. Der matol. 109:200-206.

49. McGrath, J.A., et al. 1995. Mutations in the $180-\mathrm{kD}$ bullous pemphigoid antigen (BPAG2), a transmembrane hemidesmosomal collagen (COL17A1), in generalized atrophic benign epidermolysis bullosa. Nat. Genet. 11:83-86.

50. Starkey, P.M. 1977. The effect of human neutrophil elastase and cathep$\sin \mathrm{G}$ on the collagen of cartilage, tendon, and cornea. Acta Biol. Med. Ger 36:1549-1554.

51. Gadek, J.E., Fells, G.A., Wright, D.G., and Crystal, R.G. 1980. Human neutrophil elastase functions as a type III collagen "collagenase". Biochem. Biophys. Res. Commun. 95:1815-1822.

52. Mainardi, C.L., Hasty, D.L., Seyer, J.M., and Kang, A.H. 1980. Specific cleavage of human type III collagen by human polymorphonuclear leukocyte elastase. J. Biol. Chem. 255:12006-12010.

53. Mainardi, C.L., Dixit, S.N., and Kang, A.H. 1980. Degradation of type IV (basement membrane) collagen by a proteinase isolated from human polymorphonuclear leukocyte granules. J. Biol. Chem. 255:5435-5441.

54. McDonald, J.A., and Kelly, D.G. 1980. Degradation of fibronectin by human leukocyte elastase. Release of biologically active fragments. J. Biol. Chem. 255:8848-8858

55. Malemud, C.J., and Janoff, A. Identification of neutral proteases in human neutrophil granules that degrade articular cartilage proteoglycan. Arthritis Rheum. 18:361-368.

56. Schalkwijk, J., Joosten, L.A.B., van den Berg, W.B., and van den Putte, L.B.A. 1988. Elastase secreted by activated polymorphonuclear leukocytes causes chondrocyte damage and matrix degradation in intact articular cartilage. Agents Actions. 23:58-59.

57. Hautamaki, R.D., Kobayashi, D.K., Senior, R.M., and Shapiro, S.D. 1997. Requirement for macrophage elastase for cigarette smoke-induced emphysema in mice. Science. 277:2002-2004.

58. Vu, T.H., and Werb, Z. 1998. Gelatinase B: structure, regulation, and function. In Matrix metalloproteinases. W.C. Parks and R.P. Mecham, editors. Academic Press. San Diego, CA. 115-148.

59. Welgus, H.G., et al. 1990. Neutral metalloproteinases produced by human mononuclear phagocytes. Enzyme profile, regulation, and expression during cellular development. J. Clin. Invest. 86:1496-1502.

60. Hibbs, M.S., Hasty, K.A., Seyer, J.M., Kang, A.M., and Mainardi, C.L. 1985. Biochemical and immunological characterization of secreted forms of human neutrophil gelatinase. J. Biol. Chem. 260:2493-2500.

61. Senior, R.M., et al. 1991. Human 92-kilodalton and 72-kilodalton type IV collagenases are elastases. J. Biol. Chem. 266:7870-7875.

62. Sires, U.I., et al. 1997. Degradation of entactin by matrix metalloproteinases. Susceptibility to matrilysin and identification of cleavage sites. J. Biol. Chem. 268:2069-2074.

63. Ackerman, A.B., et al. 1997. Histologic diagnosis of inflammatory skin diseases. 2nd edition. Lippincott, Williams \& Wilkins. Baltimore. 238-239.

64. Gammon, W.R., et al. 1982. An in vitro model of immune complex-mediated basement membrane zone separation caused by pemphigoid antibodies, leukocytes, and complement. J. Invest. Dermatol. 78:285-290. 